\title{
PENGARUH BIOFILTER RUMPUT LAUT Gracilaria sp. TERHADAP DOMINANSI PLANKTON PADA MEDIA AIR YANG TERPAPAR LOGAM BERAT Cr
}

\section{EFFECT OF BIOFILTER OF SEAWEED Gracilaria Sp. TO PLANKTON DOMINATION ON WATER MEDIUM THAT EXPOSED TO HEAVY METAL CHROMIUM (Cr)}

\author{
Tantika Wulan Sari, Sudarno dan Amin Alamsjah \\ Fakultas Perikanan dan Kelautan Universitas Airlangga \\ Kampus C Mulyorejo - Surabaya, 60115 Telp. 031-5911451
}

\begin{abstract}
Pollution is entered or the inclusion of living things, matter, energy, and or other components into the water. The study shows that the qualitative waters affected Sidoarjo mud Lapindo has the value of pollution index (13.3433), Sidoarjo heavily polluted coastal waters, and to sustain the cultivation of water treatments required physical, chemical and biological before the water is used for maintenance (Sudinno, 2009). Associated with the food chain, plankton have properties capable of accumulating pollutants in the environment. Pollutants in the environment are accumulated by plankton forming toxin becomes toxic compounds. There is a selection of flora and fauna to be used either as a biofilter, bioakumulator well as pollution biomonitoring agent occurs in the waters of the sea grass Gracillia sp. Giving Gracilaria sp. with different doses expected to affect the dominance of plankton in the water media exposure of heavy metals $\mathrm{Cr}$. Once the research is done, it turns out the levels of heavy metals chromium (Cr) has been dropped from the initial $0.18 \mathrm{mg} / 1$ to $0.09 \mathrm{mg} / 1$ in the sediment. There Tetraselmis chuii plankton dominance in aqueous media, dominance of plankton in the water medium to portray the diversity of aquatic environments with low plankton, and this is not good for plankton and other organisms that utilize the natural feed.
\end{abstract}

Keywords : seaweed, Gracilaria sp., heavy metals

\section{Pendahuluan}

Pencemaran adalah masuk atau dimasukkannya makhluk hidup, zat, energi, dan atau komponen lain ke dalam air. Menurut SK Menteri Kependudukan Lingkungan Hidup No 02/MENKLH/1988, pencemaran juga bisa berarti berubahnya tatanan (komposisi) air atau udara oleh kegiatan manusia dan proses alam, sehingga kualitas air/ udara menjadi kurang atau tidak dapat berfungsi lagi sesuai dengan peruntukkannya. Air permukaan dapat berkualitas baik apabila tanah sekitarnya tidak tercemar, oleh karenanya air permukaan dan air tanah dangkal sangat bervariasi kualitasnya (Herawati, 2007). Hasil studi menunjukkan bahwa secara kualitatif perairan Sidoarjo yang terkena dampak lumpur Lapindo mempunyai nilai indeks pencemaran $(13,3433)$ maka perairan pesisir Sidoarjo tercemar berat, dan untuk kelangsungan usaha budidaya diperlukan treatmen air baik secara fisik, kimia dan biologis sebelum air tersebut dimanfaatkan untuk pemeliharaan (Sudinno, 2009). Terkait dengan rantai makanan, plankton memiliki sifat mampu mengakumulasi polutan yang ada di lingkungan. Polutan yang ada di lingkungan diakumulasi oleh plankton membentuk senyawa toksin menjadi tidak toksin. Dominansi plankton merupakan salah satu indikator yang dapat digunakan untuk mengetahui struktur komunitas perairan, kesuburan perairan, sehingga dapat diketahui dalam suatu perairan terdapat tekanan ekologis yang berasal dari bahan pencemar. Terdapat pilihan flora fauna untuk dimanfaatkan baik sebagai biofilter, bioakumulator maupun sebagai agen biomonitoring pencemaran yang terjadi di perairan.

Kemampuan adaptasi yang sangat menonjol terhadap perubahan lingkungan, baik terhadap perbedaan salinitas, cahaya matahari maupun perubahan suhu yang tinggi, maka jenis rumput laut menjadi pilihan yang sangat relevan (Komarawidjaja, 2003). Integrasi rumput laut dalam upaya pemulihan kualitas air, akibat pencemaran ekosistem perairan payau, khususnya di perairan budidaya, dapat dilakukan dengan berbagai jenis teknologi, baik dengan teknologi sederhana maupun teknologi yang kompleks. Secara biologi, pengolahan limbah dengan memanfaatkan rumput laut spesies tertentu dari jenis Gracilaria, dipandang lebih berpeluang, mengingat metode aplikasi sangat sederhana, daya adaptasi yang tinggi, 
mudah pemeliharaannya, dan memiliki nilai ekonomis (Komarawidjaja, 2003).

Oleh karena itu, pengendalian dari pencemaran akan dilakukan dengan menggunakan Gracilaria sp. sebagai biofilter yang akan diuji cobakan secara laboratorium dan dominansi plankton digunakan sebagai indikator komunitas perairan serta kesuburan dalam perairan. Dengan demikian diharapkan penelitian ini dapat ditemukan jawaban apakah Gracilaria sp. dapat meminimalisir kandungan logam berat $\mathrm{Cr}$ yang terdapat di perairan, dan diharapkan dapat pula ditemukan jawaban apakah Gracilaria sp. sebagai biofilter pencemaran logam berat $\mathrm{Cr}$ dapat berdampak pada dominansi plankton di perairan tersebut yang merupakan salah satu indikator dari kesuburan perairan.

\section{Metodologi}

Penelitian ini dilaksanakan pada bulan Maret hingga April 2012 di dilakukan di Laboratorium kering dan basah Fakultas Perikanan dan Kelautan Universitas Airlangga. Proses perhitungan kandungan logam berat $\mathrm{Cr}$ pada rumput laut dilakukan Laboratorium Teknik Kimia ITS Surabaya. Peralatan yang digunakan dalam penelitian ini adalah 20 unit akuarium berukuran $(40 \times 25 \times 25) \mathrm{cm} 3$ dengan volume 20 liter air/akuarium, refraktometer, termometer, tandon air 100 liter, timbangan digital, selang, batu aerasi, mikroskop dan haemocytometer. Gracilaria sp. yang digunakan adalah Gracilaria yang didapat dengan cara membeli di Instalasi Pengembangan Bibit Rumput Laut Gracilaria sp. Desa Pulokerto, Kraton-Pasuruan. Logam berat $\mathrm{Cr}$ didapat dari Laboratorium Teknologi Lingkungan FTSP ITS Surabaya. Dalam penelitian ini dibutuhkan 3 jenis plankton yaitu: Nannochloropsis ocullata, Tetraselmis chuii, dan Skeletonema yang dibeli di BBAP Situbondo.

Penelitian ini menggunakan Rancangan Acak Lengkap (RAL) dengan lima perlakuan dan empat ulangan. Jumlah rumput laut yang digunakan dalam penelitian ini mengacu pada penelitian sebelumnya yang serupa, yaitu 100400 gram (Rahmat, 2010). Dosis logam berat $\mathrm{Cr}$ yang digunakan adalah $0,18 \mathrm{mg} / \mathrm{l}$, dosis ini didapat dari contoh sampel air yang diambil pada aliran air yang tercemar di sekitar Lapindo. Dosis plankton yg digunakan adalah 50ml untuk masing-masing plankton pada tiap-tiap akuarium, kepadatan plankton dihitung sebelum dan sesudah plankton ditebar.

Variabel yang akan diamati sesuai dengan tujuan penelitian digolongkan menjadi variabel bebas, variabel terikat, dan variabel kendali (kontrol). Variabel bebas yaitu jumlah (dosis) Gracilaria sp. tiap perlakuan. Variabel terikat yaitu dominansi plankton dan kadar logam berat $\mathrm{Cr}$ yang terdapat di Gracilaria sp. serta media air. Variabel kendali yaitu kondisi lingkungan penelitian.

Sistem pemeliharaan Gracilaria sp. dilakukan secara outdoor dan dengan sistem sirkulasi selama satu minggu dengan menggunakan akuarium berukuran 40x25×25 $\mathrm{cm} 3$, dan pada masing-masing akuarium diisi dengan air laut sebanyak 20 liter. Selama 1 minggu air laut diaerasi di dalam akuarium. Pemberian logam berat Cr 100 ppm sebanyak $36 \mathrm{ml}$ (untuk mendapatkan kandungan $\mathrm{Cr}$ di dalam air sebesar 0, $18 \mathrm{mg} / \mathrm{l}$ ) dan Gracilaria sp. pada masing-masing akuarium dilakukan seminggu setelah air laut di aerasi dan diikuti dengan pemberian ketiga jenis plankton sebanyak $50 \mathrm{ml} /$ jenis plankton.

Kelimpahan plankton dan indeks dominansi akan dihitung setiap hari dalam 1 minggu. Kelimpahan plankton dalam suatu perairan didapat dengan menghitung plankton menggunakan haemocytometer dengan metode small block.

Atomic Absorbance Spectrophotometric (AAS) digunakan untuk menganalisis kadar logam berat $\mathrm{Cr}$ yang terserap pada Gracilaria sp. Sedangkan untuk menganalisis pertambahan berat menggunakan timbangan. Analisis parameter penunjang menggunakan termometer dan refraktometer.

\section{Hasil dan Pembahasan}

Hasil penelitian pengaruh Gracilaria sp. terhadap dominansi plankton pada media air yang terpapar logam berat $\mathrm{Cr}$ menunjukkan adanya dominansi plankton. Setelah dianalisis dengan menggunakan ANAVA, dapat diketahui bahwa terdapat perbedaan yang nyata $(\mathrm{p}<0,05)$, dan setelah diuji lanjutan dengan uji berjarak Duncan maka diketahui bahwa perlakuan D memberikan pengaruh yang sangat nyata dibandingkan dengan perlakuan $\mathrm{A}, \mathrm{B}$, dan $\mathrm{C}$. Indeks dominansi plankton (D) bergerak mendekati nilai 1 yaitu plankton, Skeletonema $(0,014)$, Nannochloropsis occulata $(0,091)$ dan Tetraselmis chui $(0,291)$. Sehingga penggunaan Gracilaria sp. memiliki pengaruh terhadap dominansi plankton pada media air yang tercemar. Dominansi jenis fitoplankton dapat diketahui dengan menghitung Indeks Dominansi (D). Nilai indeks dominansi mendekati satu jika suatu komunitas didominansi oleh jenis atau spesies tertentu dan jika tidak ada jenis yang dominan, maka nilai indeks dominansinya mendekati nol (Odum, 1971). Sehingga pada 
penelitian ini dapat diketahui bahwa terdapat dominansi plankton, yaitu plankton Tetraselmis chuii hal ini dapat diketahui karena indeks dominansi (D) plankton Tetraselmis chuii yang mendekati indeks dominansi 1 yaitu sebesar 0 , 291.

Kelimpahan plankton pada penelitian ini juga diamati sebagai parameter utama. Welch (1952) mengungkapkan bahwa beberapa faktor yang mempengaruhi distribusi kelimpahan fitoplankton dalam suatu perairan adalah arus, kandungan unsur hara, predator, suhu, kecerahan, kekeruhan, $\mathrm{pH}$, gas-gas terlarut, maupun kompetitor. Hunter (1970) dalam Basmi (1988) juga mengungkapkan bahwa melimpahnya fitoplankton di suatu perairan berkaitan dengan pemanfaatan unsur hara dan radiasi sinar matahari. Selain itu, suhu, lingkungan, dan pemangsaan oleh zooplankton juga ikut berperan. Pada awal penilitian, plankton ditebar pada akuarium sebelum dilakukan perlakuan, perlakuan mulai diberikan ketika jumlah kelimpahan plankton pada tiap media dapat dianggap sama pada awal perlakuan, sehingga kelimpahan plankton pada awal perlakuan yaitu Tetraselmis chuii sebanyak 55 x 104 sel/ml, Nannochloropsis occulata sebanyak 72 x $104 \mathrm{sel} / \mathrm{ml}$, dan Skeletonema sebanyak 45 x $104 \mathrm{sel} / \mathrm{ml}$.

Zat pencemar berupa logam-logam berat merupakan masalah yang lebih serius dibandingkan dengan polutan organik karena ion-ion logam berat merupakan racun bagi organisme serta sangat sulit diuraikan secara biologi maupun kimia (Redhana 1994). Berbeda dengan logam biasa, logam berat biasanya menimbulkan efek khusus pada mahluk hidup (Palar, 1994). Hasil dari uji dengan metode ASS menunjukkan bahwa terdapat perubahan kadar logam berat kromium pada sedimen dan Gracilaria sp. Logam berat dapat menjadi bahan racun yang akan meracuni tubuh mahluk hidup, tetapi beberapa jenis logam masih dibutuhkan oleh mahluk hidup, walaupun dalam jumlah yang sedikit. Daya toksisitas logam berat terhadap makhluk hidup sangat bergantung pada spesies, lokasi, umur (fase siklus hidup), dan daya tahan (detoksikasi). Kadar kromium pada perlakuan yang semula 0,18 mg/l menjadi sekitar 0,09-0,1 mg/l pada sedimen. Perlakuan D menunjukkan kadar kromium pada sedimen paling sedikit dibandingkan dengan perlakuan lain yang masih terdapat kadar kromium hingga 0,124 mg/l, hal ini dikarenakan pada perlakuan D menggunakan Gracilaria sp. dengan dosis paling tinggi yaitu 400 gram dalam 20 liter air. Selama seminggu penelitian, kadar kromium pada Gracilaria sp. terdapat peningkatan, hal ini dapat diketahui karena kadar kromium pada Gracilaria sp. di awal penelitian yang semula $0,005 \mathrm{mg} / \mathrm{l}$ meningkat menjadi $0,083 \mathrm{mg} / \mathrm{l}$.

Toksisitas unsur $\mathrm{Cr}$ terhadap organisme perairan tergantung pada bentuk kromium, bilangan oksidasinya, dan $\mathrm{pH}$ (Hutagalung, 1991). Kadar kromium yang diperkirakan aman bagi kehidupan akuatik adalah sekitar 0,05 mg/l (Moore, 1991 dalam Effendi, 2003). Kadar maksimum kromium untuk keperluan baku air minum dan kegiatan perikanan menurut Peraturan Pemerintah No. 82 tahun 2001 adalah sebesar 0,05 mg/l.

Meskipun kadar logam berat kromium (Cr) telah turun dari semula $0,18 \mathrm{mg} / \mathrm{l}$ menjadi $0,09 \mathrm{mg} / \mathrm{l}$ pada sedimen, ini tidak bisa dianggap bahwa media air ini telah layak digunakan untuk kegiatan budidaya perairan, mengingat kadar kromium yang aman bagi kehidupan akuatik adalah sebesar $0,05 \mathrm{mg} / \mathrm{l}$. Hal lain yang menunjukkan bahwa media air dengan kadar logam berat $\mathrm{Cr}$ pada sedimen $0,09 \mathrm{mg} / \mathrm{l}$ belum dapat dikatakan layak bagi aktifitas budidaya adalah adanya dominansi plankton pada penelitian ini. Adanya dominansi plankton pada media air dapat menggambarkan lingkungan perairan dengan keanekaragaman plankton yang rendah, dan ini kurang baik bagi biota lain yang memanfaatkan plankton sebagai pakan alaminya. Namun, kemampuan Gracilaria sp. dalam biofilter logam berat kromium (Cr) sudah menunjukkan hasil yang positif, hal ini dapat dilihat dari kadar krom pada Gracilaria sp. yang meningkat karena akumulasi logam $\mathrm{Cr}$ pada Gracilaria sp. juga ikut meningkat.

\section{Kesimpulan}

Setelah melakukan penelitian tentang pengaruh Gracilaria sp. terhadap dominansi plankton pada media air yang terpapar logam berat $\mathrm{Cr}$ maka dapat ditarik kesimpulan bahwa pemberian Gracilaria sp. dengan dosis yang berbeda berpengaruh terhadap dominansi plankton pada media air yang terpapar logam berat $\mathrm{Cr}$ serta terdapat dominansi plankton Tetraselmis chuii pada media air yang menunjukkan bahwa media air masih belum dapat dikatakan layak untuk budidaya perairan.

\section{Daftar Pustaka}

Abidin. Z. 1987. Dasar-dasar Ilmu Tanah. Angkasa. Bandung.

Akoto, O. Bruce, T. N. and Darkol, G. 2008. Heavy Metals Pollution Profiles in Streams Serving The Owabi Reservoir, African Journal of Environmental 
Science and Technology, Vol. 2, No. 11, pp. 354-359.

Alamsjah, A. M., dkk. 2009. Pengaruh Kombinasi Pupuk NPK dan TSP terhadap Pertumbuhan, Kadar Air dan Klorofil a Gracilaria verrucosa. Fakultas Perikanan dan Kelautan Universitas Airlangga. Surabaya. 14 hal.

Anggadiredja, T. Dkk. 2006. Rumput Laut. Jakarta : Penerbit Penebar Swadaya.

Aslan, L. 1993. Budidaya Rumput Laut. Edisi Revisi. Yogyakarta: Penerbit Kanisius.

Basmi, J. 1988. Perkembangan Komunitas Fitoplankton Sebagai Indikasi Perubahan Tingkat Kesuburan Kwalitas Perairan. Jurusan ilmu Perairan. Fakultas Pasca Sarjana. Institut Pertanian Bogor.

Bold HC, Wynne MJ. 1985. Introduction To The Algae. Englewood (NJ): PrenticeHall.

Bougis, P. 1979. Marine Plankton Ecology. American Elsevier Publishing Company. New York.

Budiarto, E. dan D. Anggraeni. 2003.Epidemiologi. Buku Kedokteran EGC. Jakarta. hal. 135, 155.

Budiharto. 2008. Metodologi Penelitian Kesehatan dengan Contoh Bidang Ilmu Kesehatan. Buku Kedokteran EGC. Jakarta. hal. 46, 121.

Cresswell, R. C, Rees. T dan Shak, N. 1989. Algae and Cyanobacterial Biotechnology, Mc Graw Hill, London.

Dawson, E. Y. 1955. Marine Botany and Introduction. Holt, Reinhart and Winston Inc. New York: 371pp.

Diharmi. A. 2001. Pengaruh Pencahayan Terhadap Kandungan Pigmen Bioaktif Mikroalga Spirulina platensis Strain Local (Ink). Tesis Magister IPB, Bogor.

Eaton, A. D., Clesceri, L. S., dan Greenberg, A. E. 1995. APHA (American Public Health Association): Standard Method for The Examination of Water and Waste water 19th ed., AWWA (American Water Works Association), and WPCF (Water Pollution Control Federation). Washington D. C.

Effendi, H. 2003. Telaah kualitas air : Bagi pengelolaan sumberdaya dan lingkungan perairan. Penerbit kanisius. Yogyakarta.

Fitter A. H. dan Hay. R. K. M. 1991. Fisiologi Lingkungan Tanaman. Universitas Gajah Mada, Yogyakarta.
Fogg, G. E. 1987. Algal Cultures adan Phytoplankton Ecology. The Univercity of Wiconsin Press, Medison.

Gunradi, R. dan S. J. Suprapto. 2007. Penelitian Endapan Lumpur di Daerah Porong Kabupaten Sidoarjo Provinsi Jawa Timur. Kelompok Program Penelitian Konservasi. 11 hal.

Henderson-Sellers, B. and H. R. Markland. 1987. Decaying Lakes: The Origins and Control of Cultural Eutrophication.

Herawati, N. 2007. Analisis Resiko Lingkungan Aliran Air Lumpur Lapindo Ke badan Air. Universitas Diponegoro. Semarang. Tesis. 81 hal.

Hutagalung, H.P. 1991. Pencemaran laut oleh logam berat in P3O - LIPI. Jakarta.

Isnansetyo, A. dan Kurniastuty. 1995. Teknik Kultur Phytoplankton Zooplankton. Pakan Alam untuk pembenihan organism laut, Kanisius, Yogyakarta.

Komarawidjaja, W. 2003. Peluang Pemanfaatan Rumput Laut sebagai Agen Biofiltrasi pada Ekosistem Perairan Payau yang Tercemar. Badan Pengkajian dan Penerapan Teknologi. 5 hal.

Komarawidjaja, W. 2005. Rumput Laut Gracilaria sp. sebagai Fitoremedian Bahan Organik Perairan Tambak Budidaya. Pusat Pengkajian dan Penerapan Teknologi Lingkungan. Jakarta. hal 410-415.

Komarawidjaja, W. 2008. Tingkat Filtrasi Rumput Laut Gracilaria sp. terhadap Kandungan Ortofosfat (P2O5). Institut Pertanian Bogor. Bogor. hal 180-183.

Kusriningrum, R. S. 2008. Perancangan Percobaan. Airlangga University Press. Surabaya. 241 hal.

Lin, C. He, M. Zhou, Y. Guo, W. Yang, Z. 2008. Distribution and contamination assessment of heavy metals in sediment of the Second Songhua River, China, Environ Monit Assess (Springer), Vol. 137, pp. 329-342.

Liu, L., Fasheng, L., Xiong, D., 2006, Heavy Metal Contamination and Their Distribution in Different Size Fractions of The Surficial Sediment of Haihe River, China, Environ Geol, Vol 50, pp.431-438.

Marini, F. 2002. The Breeder's Net : Culturing Larval Fish Foods, Part I. http://www.advancedaquarist.com/200 2/8/breeder. 25/02/2012.

Mudjiman, A. 2004. Makanan Ikan. Edisi Revisi. Penebar Swadaya. Jakarta. 
Nybakken, J. W. 1992. Biologi Laut satu Pendekatan Ekologis. PT. Gramedia. Jakarta

Obolewski, K., Glinska-Lewczuk, K., Contents of Heavy Metals in Bottom Sediments of Oxbow Lakes and the Słupia River, Polish J. Environ. Stud. Vol. 15, No. 2a, pp. 440-44.

Odum, E. P. 1971. Fundamental Ecology. Third edition. W. B. Saunders, Co. Philadelphia. London.

Raikar, S. V, M. Lima and Y. Fujita. 2001. Effect of Temperature, Salinity and Light Intensity on the Growth of Gracilaria sp. (Gracilariales, Rhodophyta) from Japan, Malaysia and India. Journal of Marine Sciences. 30 : 98-104.

Redhana IW. 1994. Penentuan Isoterm Adsorpsi Amonia dalam Larutan Air oleh Karbon Aktif pada Suhu Kamar. Laporan Penelitian (Tidak diterbitkan) Program Pra-S2 Kimia Pascasarjana. ITB.

Reynolds, C. S. 1984. The Ecology of Freshwater Phytoplankton. Cambridge University Press. Cambridge.

Renaud, S.M. and Parry, D.L. 1991. Effect of Light Intensity on The Proximate Biochemical and Fatty Acid Composition of Isochrysis sp. And Nannochloropsis oculata For Use in Tropical Aquaculture. Journal of Applied Phicology, Vol. 3, hal. 43-53.

Sachlan., M., 1972. Planktonology. Direktorat Jendral Perikanan Departemen Pertanian, Jakarta.

Sari, C.P. 2008. Pencemaran Logam Cr (Chromium) di Sungai Serang Ditinjau Dari Kualitas Air, Cangkang Dan Struktur Mikroanatomi Insang Anodonta Woodiana Lea.

Singh, K. P., Malik, A., Sinha, S., Singh, K., Murthy, R. C., 2005, Estimation of Source of Heavy Metal Contamination in Sediments of Gomti River (India) Using Principal Component Analysis, Water, Air, and Soil Polution (Springer), Vol 166, pp. 321-341.

Sunarto. 2008. Karakteristik Biologi Dan Peranan Planktonbagi Ekosistem Laut. Fakultas Perikanan dan Ilmu Kelautan. Universitas Padjajaran.

Supartiwi, E. N. 2000. Karakteristik Komunitas Fitoplankton dan Perifiton Sebagai Indikator Kualitas Lingkungan Sungai Ciujung, Jawa Barat. Skripsi. Program
Studi Manajemen Sumberdaya Perairan. Institut Pertanian Bogor.

Taw. 1990. Petunjuk Kultur Murni dan Massal Mikroalga. UNDP. FAO

Weitzel, R. L. 1979. Methods and Measuremants of Perifiton Communities: A Review American Society for Testing and Materials. Philadelphia.

Welch, P. S. 1952. Limnology. Second edition. McGraw Hill International Book Company. New York.

Wijaya, H. K. 2009. Komunitas Perifiton Dan Fitoplankton Serta Parameter FisikaKimia Perairan Sebagai Penentu Kualitas Air Di Bagian Hulu Sungai Cisadane. Skripsi Fakultas Perikanan Dan Ilmu Kelautan Institut Pertanian Bogor. Jawa Barat.

Winarno, F. G. 1996. Teknologi Pengolahan Rumput Laut. Pustaka Sinar Harapan, Jakarta. 